\title{
Prospective cohort study of mental health during imprisonment
}

Lamiece Hassan, Luke Birmingham, Mari A. Harty, Manuela Jarrett, Peter Jones, Carlene King, Judith Lathlean, Carrie Lowthian, Alice Mills, Jane Senior, Graham Thornicroft, Roger Webb and Jenny Shaw

\section{Background}

Mental illness is common among prisoners, but little evidence exists regarding changes in symptoms in custody over time.

\section{Aims}

To investigate the prevalence and predictors of psychiatric symptoms among prisoners during early custody.

\section{Method}

In a prospective cohort study, 3079 prisoners were screened for mental illness within 3 days of reception. To establish baseline diagnoses and symptoms, 980 prisoners were interviewed; all remaining in custody were followed up 1 month and 2 months later.

\section{Results}

Symptom prevalence was highest during the first week of custody. Prevalence showed a linear decline among men and convicted prisoners, but not women or remand prisoners. It decreased among prisoners with depression, but not among prisoners with other mental illnesses.

\section{Conclusions}

Overall, imprisonment did not exacerbate psychiatric symptoms, although differences in group responses were observed. Continued discussion regarding non-custodial alternatives for vulnerable groups and increased support for all during early custody are recommended.

\section{Declaration of interest}

None.
There is concern that time spent in prison may have a detrimental impact on mental health, particularly among individuals with a pre-existing mental illness. Several large surveys in western countries have established increased prevalence of psychiatric disorders among prisoners when compared with community populations; ${ }^{1-4}$ however, there is less evidence concerning change in psychiatric symptoms during imprisonment.

A study in The Netherlands ${ }^{5}$ examined a sample of 61 prisoners with psychosis during the first 12 weeks of custody and concluded that psychotic symptoms were not exacerbated by imprisonment. Although limited in size and scope, these findings question whether prison has a universally detrimental impact on the mental health of people with pre-existing mental illness. Given that the number of prisoners in the UK with mental illness is higher than ever and rising, ${ }^{6}$ this issue is of growing importance to health professionals who work with offenders in prisons and post-release.

The aims of this study were to: (a) estimate the prevalence of psychiatric symptoms during the first 2 months of custody; and (b) identify predictors of deterioration or continued poor mental health among prisoners with and without a pre-existing mental illness.

\section{Method}

\section{Sample and procedure}

Ethical and management approvals were sought from a National Health Service (NHS) research ethics committee and NHS trusts providing mental health services at participating establishments.

This was a prospective cohort study. Newly convicted prisoners arriving at five local prisons in South East and North West England were recruited to the study. Establishments comprised three adult male prisons, one prison for adult and young men (18-21 years), and one prison for adult and young women (Table 1). A two-phase sampling design was used.

\section{Phase I: screening}

Consecutive samples of prisoners were taken from daily lists of people newly received into custody between February 2006 and April 2007. During recruitment periods, researchers aimed to approach all eligible potential participants within 3 days of reception and invite them to participate. Prisoners transferred from other establishments, non-English speaking prisoners and those deemed 'unsafe to see' were excluded. Lists were discussed only with prison officers and only to exclude ineligible participants and to unlock prisoners. Recruited participants $(n=3079)$ gave informed consent and were screened using PriSnQuest, ${ }^{7}$ an eight-item questionnaire validated to screen for mental illness in offender populations. All participants who scored three or more on PriSnQuest ('screen positives') and a 5\% sample of 'screen negatives' (scoring two or fewer) were invited to complete a full clinical interview. Table 1 reports final screening and interview figures for each prison.

\section{Phase II: clinical interview and follow-ups}

Of the 1097 participants who screened positive in Phase I, 86\% $(n=887)$ were subsequently interviewed at Phase II; mean PriSnQuest scores did not significantly differ between the interviewed and non-interviewed sample $(t=-0.39$, d.f. $=1095$, $P=0.69$ ). Comparisons between our Phase II sample and official prison population figures at individual sites indicated that the sample was broadly representative with respect to age distribution and offence characteristics. Prisoners of White ethnic origin were slightly overrepresented in our sample when compared with official prison population figures $\left(84 \%\right.$ v. $73 \% ; \chi^{2}=50.1$, d.f. $=1, P<0.01)$.

Trained researchers conducted clinical interviews with 980 prisoners within 1 week of reception into custody $\left(T_{1}\right)$. Mental illness was diagnosed using the Schedule for Affective Disorders and Schizophrenia (SADS). ${ }^{8}$ According to SADS outcome, individual participants were then assigned to one of four mutually 


\begin{tabular}{|c|c|c|c|c|c|c|c|c|}
\hline \multirow[b]{3}{*}{ Prison } & \multirow{2}{*}{\multicolumn{2}{|c|}{$\begin{array}{c}\text { Phase I } \\
\text { Screening }\end{array}$}} & \multicolumn{6}{|c|}{ Phase $\|^{a, b}$} \\
\hline & & & \multicolumn{2}{|c|}{$T_{1}$} & \multicolumn{2}{|c|}{$T_{2}$} & \multicolumn{2}{|c|}{$T_{3}$} \\
\hline & $\begin{array}{c}\text { Positive, } \\
n\end{array}$ & $\begin{array}{c}\text { Negative, } \\
n\end{array}$ & $\begin{array}{c}\text { Positive, } \\
n \text { (weight) }\end{array}$ & $\begin{array}{l}\text { Negative, } \\
n \text { (weight) }\end{array}$ & $\begin{array}{l}\text { Positive, } \\
n \text { (weight) }\end{array}$ & $\begin{array}{l}\text { Negative, } \\
n \text { (weight) }\end{array}$ & $\begin{array}{l}\text { Positive, } \\
n \text { (weight) }\end{array}$ & $\begin{array}{l}\text { Negative, } \\
n \text { (weight) }\end{array}$ \\
\hline A: Adult male local - high secure & 148 & 429 & $146(1.01)$ & $22(19.50)$ & $78(1.90)$ & $10(42.90)$ & $10(14.80)$ & 0 (na) \\
\hline B: Adult and young female local & 228 & 285 & $199(1.15)$ & $12(23.75)$ & $124(1.84)$ & $10(28.50)$ & $20(11.40)$ & 0 (na) \\
\hline C: Adult and young male local & 262 & 427 & $222(1.18)$ & 40 (10.68) & $132(1.99)$ & $26(16.42)$ & $68(3.85)$ & $15(28.47)$ \\
\hline D: Adult male local - high secure & 231 & 452 & $195(1.19)$ & 15 (30.13) & $125(1.85)$ & $11(41.09)$ & $62(3.73)$ & $7(64.57)$ \\
\hline E: Adult male local & 228 & 389 & $125(1.82)$ & $4(97.25)$ & $54(4.22)$ & $2(194.50)$ & 0 (na) & 0 (na) \\
\hline All & 1097 & 1982 & $887(1.24)$ & $93(21.31)$ & $513(2.14)$ & 59 (33.59) & $160(6.86)$ & $22(90.09)$ \\
\hline
\end{tabular}

exclusive and hierarchical diagnostic categories: any psychosis major depressive disorder (excluding any psychoses); other mental illness (including minor depressive disorder, general anxiety disorder, obsessive-compulsive disorder and phobias; excluding any psychoses and/or major depressive disorder); and none. Baseline measures of psychiatric symptoms were taken at $T_{1}$ using the 12-item General Health Questionnaire (GHQ-12) ${ }^{9}$ and the expanded Brief Psychiatric Rating Scale (BPRS-E). ${ }^{10}$

Those remaining in prison were approached for follow-up interviews at 1 month ( $T_{2}, 3-5$ weeks) and 2 months ( $T_{3}, 7-9$ weeks) into custody. The BPRS-E and GHQ-12 were re-administered at each follow-up. Table 2 reports sample size and characteristics at $T_{1}, T_{2}$ and $T_{3}$. Of the 980 prisoners interviewed at $T_{1}, 58 \%$ were followed up at $T_{2}$ and $19 \%$ were followed up at $T_{3}$. Attrition at each stage was primarily due to prisoners being released or transferred to other prisons. Samples were proportionally similar across the three time points with respect to the demographic, forensic and clinical characteristics measured.

\section{Outcome measures}

The GHQ-12 was used as the principal measure of mental wellbeing. Items were scored using the dichotomous style $(0 ; 0 ; 1 ; 1)$ scoring procedure. In UK community samples, a total GHQ-12 score of three or more is routinely used as a cut-off value for establishing caseness. In prison populations, however, higher thresholds offer a superior balance of sensitivity and specificity. ${ }^{11,12}$ In line with previous research, a cut-off of seven or more was used, henceforth referred to as 'GHQ prison caseness'.

The BPRS-E was used to measure 24 separate psychiatric symptoms. Symptoms were rated on a Likert scale (range 1-7), using a score of four or more on any individual item as the threshold to indicate clinical severity. Analysis focuses on one BPRS-E item, namely 'suicidality', defined as the 'expressed desire, intent, or actual actions to harm or kill self.' ${ }^{10}$

\section{Statistical analysis}

The GHQ-12 scores and BPRS-E item scores for suicidality were converted into dichotomous outcomes (above/below cut-off). Analyses were conducted using Stata version 10 software for Windows and with two-sided statistical significance defined as $P<0.05$.

Sampling probability weights were calculated (Table 1) according to PriSnQuest screening outcomes and applied to prevalence estimates and regression analyses to derive valid point

\begin{tabular}{|c|c|c|c|}
\hline & $T_{1}$ & $T_{2}$ & $T_{3}$ \\
\hline \multicolumn{4}{|l|}{ Demographic } \\
\hline Male, $n(\%)$ & $769(78)$ & $438(77)$ & $162(89)$ \\
\hline Age, years: mean (s.d.) & $32.9(8.7)$ & $32.8(8.8)$ & $33.1(9.2)$ \\
\hline White, $n(\%)$ & $820(84)$ & $478(84)$ & $153(85)$ \\
\hline Married, $n(\%)$ & $351(36)$ & $208(36)$ & $60(33)$ \\
\hline \multicolumn{4}{|l|}{ Forensic, $n(\%)$} \\
\hline Convicted & $474(48)$ & $273(48)$ & $77(42)$ \\
\hline Violent index offence & $216(22)$ & $136(24)$ & $40(22)$ \\
\hline \multicolumn{4}{|l|}{ Clinical, $n$ (\%) } \\
\hline \multicolumn{4}{|l|}{ Psychiatric diagnosis } \\
\hline Any psychosis & $101(10)$ & $53(9)$ & $16(9)$ \\
\hline Major depressive disorder & $318(32)$ & $181(32)$ & $56(31)$ \\
\hline Any mental illness & $122(12)$ & 73 (13) & $30(17)$ \\
\hline None & $439(45)$ & $265(46)$ & $80(44)$ \\
\hline Dual diagnosis & $454(46)$ & $259(45)$ & $84(46)$ \\
\hline Drug misuse & $658(67)$ & $386(67)$ & $118(65)$ \\
\hline Alcohol misuse & $506(52)$ & $287(50)$ & $84(46)$ \\
\hline Prior contact with MHS (lifetime) & $436(45)$ & $239(42)$ & $64(35)$ \\
\hline Receiving MHS in prison (current) ${ }^{\mathrm{b}}$ & 87 (9) & $60(11)$ & $21(12)$ \\
\hline All & $980(100)$ & $572(100)$ & $182(100)$ \\
\hline $\begin{array}{l}\text { MHS, mental health services. } \\
\text { a. Unweighted percentage. } \\
\text { b. At any time during study period. }\end{array}$ & & & \\
\hline
\end{tabular}


and variance estimates from the two-phase sampling design. Discrete weights were derived for each prison and each time point, thus accounting for sample attrition at $T_{2}$ and $T_{3}$. Weighted prevalence and variance estimates were obtained from the coefficients generated by logistic regression models, as described by Dunn et al. ${ }^{13}$ Chi-squared tests were used to test for heterogeneity and linear trends between prevalence rates at $T_{1}$, $T_{2}$ and $T_{3}$.

Univariate analysis was used to identify predictors of change in psychiatric symptoms over the period $T_{1}$ to $T_{2}$. This particular analysis was restricted to this period in order to maximise sample size. Analysis focused on the two change outcomes of key clinical importance, defined using combinations of outcomes at $T_{1}$ and $T_{2}$ : deteriorating ( $T_{1}$ below, $T_{2}$ above) and remaining above cutoff ( $T_{1}$ above, $T_{2}$ above). Weighted binomial regression was then used to estimate risk ratios and their 95\% confidence intervals for change outcomes according to gender, legal status and serious mental illness status, defined as any psychosis and/or major depressive disorder. Estimates for gender and legal status were further adjusted for serious mental illness in multivariate models.

\section{Results}

\section{Gender}

At $T_{1}, 46 \%$ of women and $33 \%$ of men met the cut-off for GHQ prison caseness (Table 3). Rates of GHQ prison caseness over the period $T_{1}-T_{3}$ showed a significant linear decrease among men, but not women. At $T_{3}$, rates of GHQ prison caseness were significantly higher among women than men $\left(\chi^{2}=7.60\right.$, d.f. $\left.=1, P<0.01\right)$.
At $T_{1}$, significantly more men than women had clinical symptoms of suicidality (Table $4 ; \chi^{2}=6.79$, d.f. $=1, P<0.01$ ). Clinical symptoms of suicidality showed a significant linear decrease over the period $T_{1}-T_{3}$ among men, but not women. Clinical symptoms of suicidality remained significantly more prevalent among women than men at $T_{3}\left(\chi^{2}=7.27\right.$, d.f. $=1$, $P<0.01)$.

\section{Legal status}

At $T_{1}, 44 \%$ of remand and $28 \%$ of convicted prisoners met the GHQ prison cut-off for caseness $\left(\chi^{2}=5.54\right.$, d.f. $\left.=1, P=0.02\right)$. Over the period $T_{1}-T_{3}$ there was a significant linear decrease in rates of GHQ prison caseness among convicted prisoners. No significant differences were observed in caseness rates among remand prisoners over the same period. Rates of GHQ prison caseness were significantly higher among remand prisoners than in convicted prisoners at $T_{3}\left(\chi^{2}=7.42\right.$, d.f. $\left.=1, P<0.01\right)$.

Clinical symptoms of suicidality were significantly more prevalent among remand than convicted prisoners at $T_{1}$ $\left(\chi^{2}=5.07\right.$, d.f. $\left.=1, P=0.02\right)$. Clinical symptoms of suicidality showed a significant linear decrease over $T_{1}-T_{3}$ among convicted but not remand prisoners. At $T_{3}$ there were no significant differences in rates of clinical symptoms of suicidality between remand and convicted prisoners $\left(\chi^{2}=1.39\right.$, d.f. $\left.=1, P=0.24\right)$.

\section{Psychiatric diagnosis}

The GHQ prison caseness at $T_{1}$ was highest among both prisoners with psychosis and those with major depressive disorder. Over

\begin{tabular}{|c|c|c|c|c|c|c|c|c|}
\hline & \multicolumn{2}{|c|}{$T_{1}$} & \multicolumn{2}{|c|}{$T_{2}$} & \multicolumn{2}{|c|}{$T_{3}$} & \multicolumn{2}{|c|}{ Change $T_{1}-T_{3}$} \\
\hline & $n$ & $\%(95 \% \mathrm{Cl})$ & $n$ & $\%(95 \% \mathrm{Cl})$ & $n$ & $\%(95 \% \mathrm{Cl})$ & Heterogeneity & Linearity \\
\hline \multicolumn{9}{|l|}{ Gender } \\
\hline Men & 469 & $33(26-41)$ & 167 & $23(16-32)$ & 43 & $18(10-29)$ & $P=0.03$ & $P=0.01$ \\
\hline Women & 146 & $46(31-61)$ & 72 & $28(18-40)$ & 10 & $50(29-71)$ & $P=0.02$ & $P=0.84$ \\
\hline \multicolumn{9}{|l|}{ Legal status } \\
\hline Remand & 342 & $44(34-55)$ & 106 & $39(26-53)$ & 33 & $37(22-55)$ & $P=0.78$ & $P=0.49$ \\
\hline Convicted & 272 & $28(20-37)$ & 129 & $17(11-26)$ & 20 & $13(7-22)$ & $P<0.01$ & $P<0.01$ \\
\hline \multicolumn{9}{|l|}{ Psychiatric diagnosis } \\
\hline Any psychosis & 72 & $73(63-81)$ & 30 & $54(40-68)$ & 8 & $56(28-81)$ & $P=0.03$ & $P=0.20$ \\
\hline Major depressive disorder & 249 & $73(62-82)$ & 108 & $53(39-67)$ & 24 & $45(30-60)$ & $P=0.01$ & $P<0.01$ \\
\hline Other mental illness & 76 & $28(15-48)$ & 24 & $24(7-58)$ & 11 & $56(27-82)$ & $P=0.14$ & $P=0.25$ \\
\hline None & 218 & $25(18-33)$ & 77 & $14(8-24)$ & 10 & $7(3-16)$ & $P<0.01$ & $P<0.001$ \\
\hline
\end{tabular}

\begin{tabular}{|c|c|c|c|c|c|c|c|c|}
\hline & \multicolumn{2}{|c|}{$T_{1}$} & \multicolumn{2}{|c|}{$T_{2}$} & \multicolumn{2}{|c|}{$T_{3}$} & \multicolumn{2}{|c|}{ Change $T_{1}-T_{3}$} \\
\hline & $n$ & $\%(95 \% \mathrm{Cl})$ & $n$ & $\%(95 \% \mathrm{Cl})$ & $n$ & $\%(95 \% \mathrm{Cl})$ & Heterogeneity & Linearity \\
\hline \multicolumn{9}{|l|}{ Gender } \\
\hline Men & 143 & $8(6-11)$ & 34 & $5(2-10)$ & 10 & $3(1-5)$ & $P<0.001$ & $P<0.001$ \\
\hline Women & 65 & $16(11-24)$ & 28 & $10(6-16)$ & 3 & $15(5-38)$ & $P=0.03$ & $P=0.70$ \\
\hline \multicolumn{9}{|l|}{ Legal status } \\
\hline Remand & 122 & $12(8-17)$ & 30 & $11(5-24)$ & 7 & $6(3-14)$ & $P=0.31$ & $P=0.10$ \\
\hline Convicted & 86 & $7(5-10)$ & 31 & $3(2-5)$ & 6 & $3(1-7)$ & $P<0.001$ & $P=0.01$ \\
\hline \multicolumn{9}{|l|}{ Psychiatric diagnosis } \\
\hline Any psychosis & 42 & $45(35-55)$ & 14 & $24(15-38)$ & 3 & $22(6-56)$ & $P=0.02$ & $P=0.11$ \\
\hline Major depressive disorder & 107 & $32(24-42)$ & 26 & $18(8-38)$ & 4 & $7(2-20)$ & $P=0.002$ & $P<0.001$ \\
\hline Other mental illness & 22 & $6(3-12)$ & 5 & $3(1-11)$ & 1 & $6(1-33)$ & $P=0.48$ & $P=0.78$ \\
\hline None & 37 & $2(2-3)$ & 17 & $2(1-3)$ & 5 & $2(1-4)$ & $P=0.55$ & $P=0.43$ \\
\hline
\end{tabular}


the period $T_{1}-T_{3}$, GHQ prison caseness rates significantly declined in prisoners with major depressive disorder and with no mental illness. Among prisoners with any psychosis, GHQ prison caseness rates showed significant heterogeneity over $T_{1}-T_{3}$, but not linearity. No statistically significant differences were observed among prisoners with any other mental illness over the study period.

At $T_{1}$, clinical symptoms of suicidality were most prevalent among participants with psychosis (45\%) and with major depressive disorder (32\%). Over $T_{1}-T_{3}$, clinical symptoms of suicidality reduced among prisoners with severe mental illness (psychosis and/or major depressive disorder): significant heterogeneity was found across the three time points among both prisoners with any psychosis and prisoners with major depressive disorder, with the latter also demonstrating a significant downward linear trend. No significant trends were observed in prisoners with any other mental illness or no mental illness.

\section{Predictors of change in mental health}

Table 5 presents risk ratio estimates for change outcomes (deteriorating and remaining above cut-off) according to gender, legal status and severe mental illness. Using the GHQ prison caseness measure, the risk ratio was significantly higher in prisoners with severe mental illness than those without for remaining above cut-off, but not deteriorating. Using the BPRS-E measure of clinical symptoms of suicidality, risk ratios were significantly higher in prisoners with severe mental illness than those without for both deteriorating and remaining above cut-off.

Using the GHQ prison caseness measure, the relative risk of deteriorating was significantly higher in remand prisoners than convicted prisoners, and remained significant after adjusting for severe mental illness. Using the BPRS-E measure of clinical symptoms of suicidality, risk ratios were significantly higher in remand prisoners than in convicted prisoners for both deteriorating and remaining above cut-off; after adjusting for severe mental illness, remand status only significantly predicted deterioration. There were no significant gender differences in relative risk for either deteriorating or remaining above cut-off using either measure; risk ratios were materially unaltered following adjustment for drug dependence.

\section{Discussion}

\section{Overall trends}

During the first 2 months of custody, psychiatric symptoms did not significantly increase in any group from our sample. We found significant linear decreases in symptom intensity in three groups: men, convicted prisoners and individuals with major depressive disorder. Our findings suggest that imprisonment may not have a universally detrimental impact on mental health, even among those with pre-existing mental illness. These findings are consistent with previous studies which found that psychiatric symptoms generally stabilised or decreased during custody. ${ }^{5,14-17}$ Previously, authors have speculated whether positive outcomes might be attributed to factors such as safety, structure, reduced drug and alcohol consumption, and access to medication and healthcare services. ${ }^{5,14}$

Levels of distress were high in the first week of custody among all newly received prisoners. Symptoms were not exclusive to prisoners with mental illness; though a higher threshold was adopted, $25 \%$ of prisoners with no mental illness met the GHQ prison cut-off for caseness at $T_{1}$. Using the standard community cut-off (three), this figure would have risen to $60 \%$. Our findings are consistent with previous studies that have highlighted early custody as a period of significant vulnerability and heightened risk. ${ }^{14,18,19}$ Such concern is justified given that a national clinical survey found that a third of prison suicides happened within the first week of custody. ${ }^{19}$

\section{Group differences in response to imprisonment}

Symptoms declined significantly among men, but not women. The notion that women are differently and disproportionately

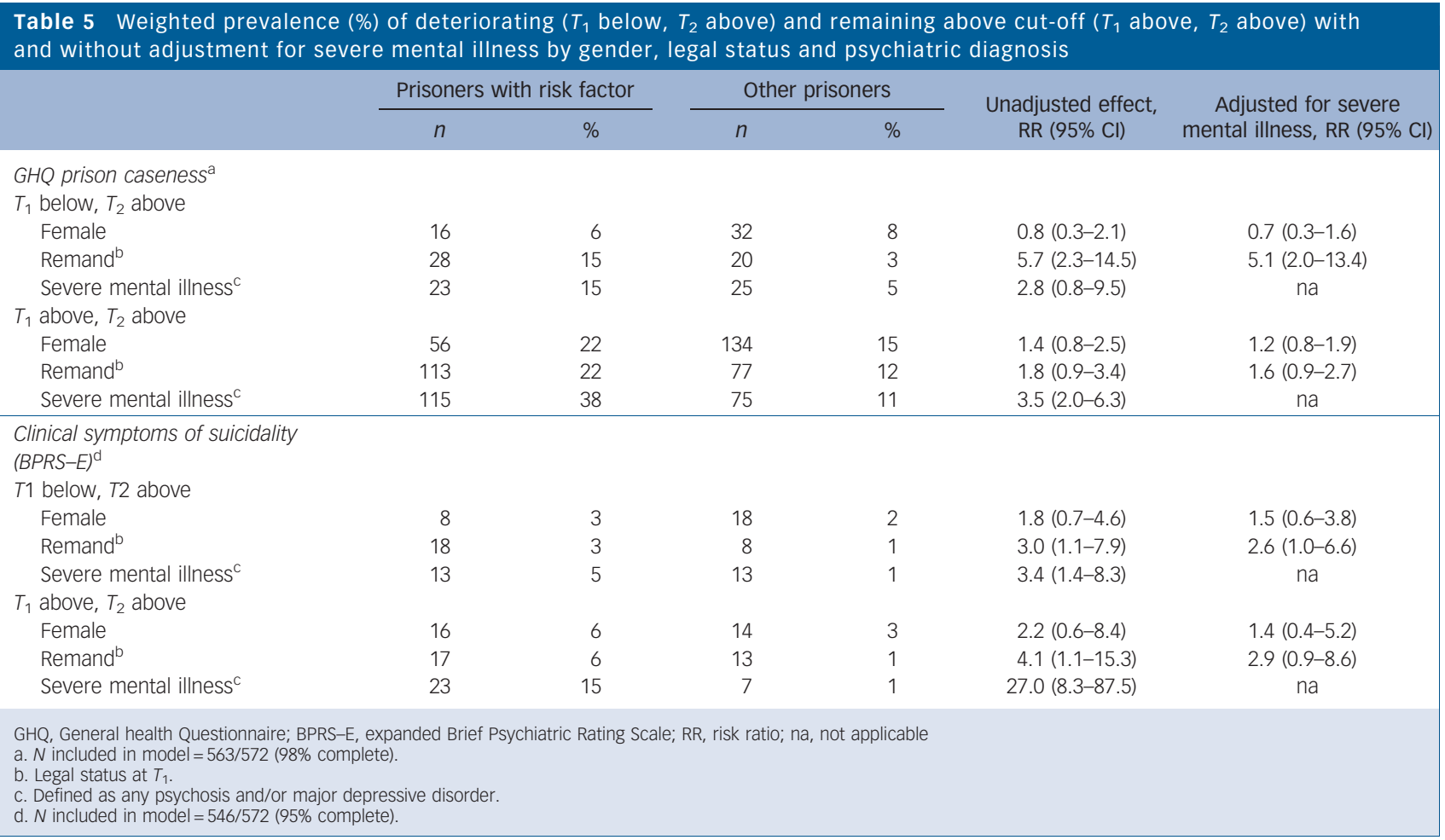


affected by imprisonment is well supported in the literature. Family life is often greatly disrupted: a third of women lose their homes and just $5 \%$ of children remain in their own home once their mother has been imprisoned. ${ }^{20}$ Also, because there are fewer female prisons, women are often located further from their homes making it harder to receive visits. ${ }^{21}$ Women prisoners are more likely to have 'imported vulnerability'; ${ }^{18}$ in particular, pre-existing psychiatric, self-harm and substance misuse problems. ${ }^{4}$ Last, Corsten ${ }^{22}$ argues that custodial sentences are harsher on women because prison regimes and practices have been designed for men.

Symptoms declined significantly among convicted prisoners, but not remand prisoners. Remand status significantly predicted mental health deterioration, even after adjustment for severe mental illness. It is plausible that the additional stresses associated with being a remand prisoner, including repeated court visits and considerable uncertainty regarding the future, may have contributed to sustained symptoms. Previous studies have reported higher rates of psychiatric morbidity and suicide in the remand population. ${ }^{4,19}$ Isolation and lack of mental stimulation have been noted as a significant source of stress and frustration among remand prisoners, who often have limited access to education or work. ${ }^{23}$

Imprisonment generally did not exacerbate psychiatric symptoms in prisoners with severe mental illness. We observed significant linear decreases in symptoms among prisoners with major depressive disorder, and non-significant decreases among prisoners with psychosis. These findings are consistent with a study ${ }^{5}$ that attributed the improvements observed to safety, structure and access to psychiatric care in prison. In a minority of cases, symptoms persisted or further deteriorated. Severe mental illness was a significant predictor of continued poor mental health and deterioration. It is unclear why symptoms failed to stabilise among some individuals: possibly they possessed additional characteristics that increased their vulnerability.

Symptoms did not significantly reduce among prisoners diagnosed with any other mental illness. In this group symptoms peaked at $T_{3}$. This finding could merely be an attrition-related anomaly; alternatively, it could hint at problems with service provision for this group. Indeed, UK prison in-reach services largely focus on severe mental illness and often primary mental healthcare services are absent or underdeveloped. ${ }^{24}$ Thus, it is unclear what support is routinely available for less serious mental health problems.

\section{Strengths and limitations}

This is the largest prospective cohort study in the UK to monitor clinical changes in psychiatric symptoms among the general population of prisoners entering custody. It represents a novel contribution in a field well-populated by point-prevalence studies. Much of the previous longitudinal work in this area has used small $(n<100)$ sample sizes, ${ }^{5,16}$ or has been limited to a single follow-up, ${ }^{15-17}$ prison ${ }^{14-16}$ or psychiatric diagnosis. ${ }^{5}$ Nonetheless, our study is not without limitations.

The study chose the GHQ-12, an extensively validated selfreport measure, ${ }^{25}$ as the principal measure of change in mental well-being. Although the GHQ is widely recognised and used for screening purposes, retest effects have been demonstrated when used repeatedly over shorter periods. ${ }^{26}$ However, the same study found that effects were limited to differences in the first two assessments, ${ }^{26}$ which would not explain the linear reductions in scores observed in this study over three time points. Additionally, it does not explain the differential changes in symptom prevalence between the different groups observed. We take further confidence in that trends identified using the GHQ-12 and BPRS-E were similar to each other and to those reported by previous studies that used versions of these tools ${ }^{5,15,16}$ or alternative measures. ${ }^{17}$

This study focused on exploring specific risk factors: gender, legal status and psychiatric diagnosis. These were prioritised a priori over other demographic, criminological and clinical factors measured in the sample. Although selective, in our opinion these represent fundamental variables within forensic psychiatry relevant to categorising adult receptions into prison and feature prominently in the existing literature considering alternatives to custody for vulnerable groups. ${ }^{6,20,21}$ It is inevitable, however, that other unmeasured or unexplored factors exerted unknown influences on mental health in the sample, such as drug withdrawal, prison experience and care in custody. This study should therefore be regarded as a platform from which future investigators can develop further work incorporating alternative combinations of risk factors.

As others have acknowledged, ${ }^{17}$ conducting longitudinal research in local prisons is complicated by the high turnover of prisoners and the proportion serving short sentences. This creates two reciprocally related problems: attrition bias and short duration of follow-up. Despite our best efforts to retain participants, many were released or transferred from prison. However, overall sample composition was not greatly altered and appropriate weighting was applied to prevalence estimates to correct for non-random attrition over time. Although we believe that participants who developed symptoms during the study were no more likely to have withdrawn or to have been discharged, this possibility cannot be completely ruled out. A longer follow-up period would have been preferred to determine whether the initial improvements we observed were sustained over the longer term. In a different type of study, sites with more stable populations (e.g. training prisons) might have been selected to enable longer follow-up periods. For the purposes of this study, however, it was important to sample local prisons to avoid excluding vulnerable offender populations; indeed, two-thirds of all prison suicides in England and Wales take place in local prisons. ${ }^{27}$

\section{Implications}

Policy-makers and practitioners on both sides of the prison wall should take note of the findings of this study, while bearing in mind its limitations. It appears that the first 2 months of imprisonment do not have a universally detrimental impact on mental health, even among those with pre-existing mental illnesses. However, individuals may be affected differently, with poorer responses apparent in women, remand prisoners and those with pre-existing mental illnesses. Furthermore, our findings confirm that the first week of custody continues to represent a period of heightened distress and risk among all newly received prisoners.

The 'diversion agenda' has gathered momentum in recent years, with increasing calls for non-custodial alternatives for vulnerable groups. ${ }^{6,22}$ By reporting group differences in response to early imprisonment, our findings may usefully contribute to the growing policy and research literature surrounding this debate. Growth in the UK prison population means that for the foreseeable future, the number of people with mental illness in prisons is expected to rise. ${ }^{6}$ Furthermore, early custody remains a critical stage for many prisoners without a diagnosable mental illness. Thus, in addition to continuing discussions regarding diversion, improving primary and secondary mental health services and implementing robust early support systems for all 
prisoners who need it should remain key priorities. Models of mental healthcare provision must continue to grow, develop and diversify if the public health opportunities of prison healthcare reform are to be fully realised.

Lamiece Hassan, MPhil, Lancashire Care NHS Foundation Trust and The University of Manchester; Luke Birmingham, MRCPsych, PhD, Hampshire Partnership Foundation NHS Trust and University of Southampton, Knowle; Mari A. Harty FRCPsych, PhD; Manuela Jarrett, RMN, MSc, Institute of Psychiatry, King's College London; Peter Jones, FRCPsych, PhD, University of Cambridge; Carlene King, MSC, The University of Manchester; Judith Lathlean, DPhil, The University of Southampton; Carrie Lowthian, RNMH, MSC, The University of Manchester; Alice Mills, PhD, The University of Southampton; Jane Senior, RMN, PhD, The University of Manchester; Graham Thornicroft, FRCPsych, PhD, Institute of Psychiatry, King's College London; Roger Webb, PhD; Jenny Shaw, FRCPsych, PhD, The University of Manchester, UK

Correspondence: Lamiece Hassan, University of Manchester, Room 2.314, Jean MCFarlane Building, Oxford Road, Manchester M13 9PL, UK. Email: lamiece.hassan@nhs.net

First received 22 Mar 2010, final revision 16 Jul 2010, accepted 6 Oct 2010

\section{Funding}

This study was funded by the National Programme on Forensic Mental Health Research and Development at the Department of Health.

\section{Acknowledgements}

We thank the following colleagues for their invaluable contributions to the study: Charlie Brooker, Ruth Clayton, George Coffee, Nicola Coxon, Kirsty Foster, Dina Gojkovic, Kevin Gournay, Julia Hookway, Kathy Justo, Paul Kelly, Kathy Kendall, Paul Ralphs, Tom Ricketts, Mariamne Rose, Julie Steel \& Donald Toseafa. We also gratefully acknowledge the practical help and assistance given to the research team by prison discipline and healthcare staff and managers in facilitating our work in the study sites.

\section{References}

1 Brooke D, Taylor C, Gunn J, Maden A. Point prevalence of mental disorder in unconvicted male prisoners in England and Wales. BMJ 1996; 313: 1524-7.

2 Brugha $\mathrm{T}$, Singleton $\mathrm{N}$, Meltzer $\mathrm{H}$, Bebbington $\mathrm{P}$, Farrell $\mathrm{M}$, Jenkins $\mathrm{R}$. Psychosis in the community and in prisons: a report from the British National Survey of psychiatric morbidity. Am J Psychiatry 2005; 162: 774-80.

3 Fazel S, Danesh J. Serious mental disorder in 23000 prisoners: a systematic review of 62 surveys. Lancet 2002; 359: 545-50.

4 Singleton N, Meltzer H, Gatward R. Psychiatric Morbidity among Prisoners in England and Wales. Office of National Statistics, 1998.

5 Blaauw E, Roozen $H$, Val Marle $H$. Saved by structure? The course of psychosis within a prison population. Int J Prison Health 2007; 3: 248-56.

6 Bradley K. The Bradley Report: Lord Bradley's Review of People with Mental Health Problems or Learning Disabilities in the Criminal Justice System. Department of Health, 2009.
7 Shaw J, Tomenson B, Creed F. A screening questionnaire for the detection of serious mental illness in the criminal justice system. J Forensic Psychiatr Psychol 2003; 1: 138-50.

8 Endicott J, Spitzer RL. A diagnostic interview: the schedule for affective disorders and schizophrenia. Arch Gen Psychiatry 1978; 35: 837-44.

9 Goldberg D. GHQ-12. nferNelson, 1978.

10 Lukoff D, Liberman RP, Nuechterlein KH. Symptom monitoring in the rehabilitation of schizophrenic patients. Appendix A. Schizophr Bull 1986; 12: 594-602.

11 Andersen HS, Sestoft D, Lillebæk T, Gabrielsend G, Hemmingsen R. Validity of the General Health Questionnaire (GHQ-28) in a prison population: data from a randomized sample of prisoners on remand. Int J Law Psychiatry 2002; 25: $573-80$

12 Senior J. The development of prison mental health services on a community mental health model [PhD Thesis]. Faculty of Medical and Human Sciences, University of Manchester, 2005

13 Dunn G, Pickles A, Tansella M, Vazquez-Barquero JL. Two-phase epidemiological surveys in psychiatric research. Br J Psychiatry 1999; 174: 95-100.

14 Andersen HS, Sestoft D, Lillebaek T, Gabrielsen G, Hemmingsen R. A longitudinal study of prisoners on remand: repeated measures of psychopathology in the initial phase of solitary versus nonsolitary confinement. Int J Law Psychiatry 2003; 26: 165-77.

15 Harding T, Zimmermann E. Psychiatric symptoms, cognitive stress and vulnerability factors. A study in a remand prison. Br J Psychiatry 1989; 155 36-43.

16 Hurley W, Dunne MP. Psychological distress and psychiatric morbidity in women prisoners. Aust NZ J Psychiatry 1991; 25: 461-70.

17 Taylor PJ, Walker J, Dunn E, Kissell A, Williams A, Amos T. Improving mental state in early imprisonment. Crim Behav Ment Health 2010; 20: 215-31.

18 Liebling A, Tait S, Durie L, Stiles A, Harvey J. Safer locals evaluation. Prison Serv J 2005; 162: 8-12.

19 Shaw J, Baker D, Hunt IM, Moloney A, Appleby L. Suicide by prisoners. National clinical survey. Br J Psychiatry 2004; 184: 263-7.

20 Prison Reform Trust. Justice for Women: The Need for Reform. Prison Reform Trust, 2000.

21 Social Exclusion Unit. Reducing Offending by Ex-prisoners. Social Exclusion Unit, 2002.

22 Corsten J. The Corsten Report. Home Office, 2006.

23 Nurse J, Woodcock P, Ormsby J. Influence of environmental factors on mental health within prisons: focus group study. BMJ 2003; 327: 480 .

24 Steel J, Thornicroft G, Birmingham L, Brooker C, Mills A, Harty M, et al. Prison mental health inreach services. Br J Psychiatry 2007; 190: 373-4.

25 Goldberg DP, Gater R, Sartorius N, Ustun TB, Piccinelli M, Gureje O, et al. The validity of two versions of the GHQ in the WHO study of mental illness in general health care. Psychol Med 1997; 27: 191-7.

26 Ormel J, Koeter MW, van den Brink W. Measuring change with the Genera Health Questionnaire (GHQ). The problem of retest effects. Soc Psychiatry Psychiatr Epidemiol 1989; 24: 227-32.

27 HM Chief Inspector of Prisons for England and Wales. Annual Report 2008-09. TSO (The Stationery Office), 2010. 